\title{
Natural Infection of Cashew (Anacardium occidentale) by Xanthomonas citri pv. mangiferaeindicae in Burkina Faso
}

C. Zombre and P. Sankara, Université de Ouagadougou, Ecole doctorale Science et Technologie, Ouagadougou, Burkina Faso; S. L. Ouédraogo and I. Wonni, Institut de l'Environnement et de Recherches Agricoles, Bobo Dioulasso, Burkina Faso; and K. Boyer, C. Boyer, M. Terville, S. Javegny, A. Allibert, C. Vernière, and O. Pruvost, CIRAD, UMR PVBMT, F-97410 Saint Pierre, La Réunion, France

\begin{abstract}
Zombre, C., Sankara, P., Ouédraogo, S. L., Wonni, I., Boyer, K., Boyer, C., Terville, M., Javegny, S., Allibert, A., Vernière, C., and Pruvost, O. 2016. Natural infection of cashew (Anacardium occidentale) by Xanthomonas citri pv. mangiferaeindicae in Burkina Faso. Plant Dis. 100:718-723.

Xanthomonas citri pv. mangiferaeindicae is the causal agent of bacterial canker of mango (Mangifera indica, Anacardiaceae), a disease of international importance. Since the original description of the bacterium in the 1940s, the status of cashew (Anacardium occidentale, Anacardiaceae) as a host species has been unclear. Here, we report the first outbreak of a cashew bacterial disease in Burkina Faso (Western Africa) where $X$. citri pv. mangiferaeindicae recently emerged on mango. A comprehensive molecular characterization, based on multilocus sequence analysis, supplemented with pathogenicity assays of isolates obtained during the outbreak, indicated that the causal agent on cashew in Burkina Faso is

$X$. citri pv. mangiferaeindicae and not $X$. citri pv. anacardii, which was previously reported as the causal agent of a cashew bacterial leaf spot in Brazil. Pathogenicity data supported by population biology in Burkina Faso suggest a lack of host specialization. Therefore, the inoculum from each crop is potentially harmful to both host species. Symptoms induced on cashew leaves and fruit by $X$. citri pv. mangiferaeindicae and nonpigmented strains of $X$. citri pv. anacardii are similar, although the causative bacteria are genetically different. Thus, xanthomonads pathogenic on cashew may represent a new example of pathological convergence in this bacterial genus.
\end{abstract}

Mango (Mangifera indica) bacterial canker (MBC), also named bacterial black spot, caused by Xanthomonas citri pv. mangiferaeindicae (syn. $X$. axonopodis pv. mangiferaeindicae), is a threat to this Anacardiaceae species in many tropical and subtropical countries (Ah-You et al. 2009; Gagnevin and Pruvost 2001). The pathogen has been reported in several regions of the world where mango is grown (Asia, Southern and Eastern Africa, Oceania, and the Indian Ocean region) (Gagnevin and Pruvost 2001). MBC has recently emerged in Western Africa. In 2010, it was identified in Ghana (Pruvost et al. 2011a), Burkina Faso (Pruvost et al. 2011b), and Mali (Pruvost et al. 2012) and, in 2014, in the Ivory Coast (Pruvost et al. 2014) and Benin (Zombre et al. 2015).

Severe MBC infections inducing considerable leaf or fruit drop and a reduction in yield of up to $80 \%$ have been reported on highly susceptible mango cultivars (Kishun 1982). Mango originated from the Indian subcontinent (Mukherjee 1997) and X. citri pv. mangiferaeindicae may have originated from the same region, because symptoms of the disease were first observed in a herbarium specimen collected in Bihar, India in 1881 (Patel et al. 1948). A detailed description of MBC symptomatology as well as the biology and epidemiology of the pathogen have been published previously (Gagnevin and Pruvost 2001). The first description of the bacterium causing MBC was published in 1948 (Patel et al. 1948). X. citri pv. mangiferaeindicae is culturally atypical compared with most xanthomonads, because it produces nonpigmented (i.e., creamy white) colonies (Manicom and Wallis 1984). This characteristic was recently explained by the deletion of several genes in the xanthomonadin (yellow) pigment gene cluster (Midha and Patil 2014).

Corresponding author: O. Pruvost; E-mail: olivier.pruvost@cirad.fr

*The $\boldsymbol{e}$-Xtra logo stands for "electronic extra" and indicates that two supplementary tables are published online.

Accepted for publication 16 November 2015.

http://dx.doi.org/10.1094/PDIS-10-15-1137-RE

(C) 2016 The American Phytopathological Society
The pathovar derives its name from mango, the host species from which the pathogen was originally isolated and described (Dye et al. 1980; Patel et al. 1948). In addition to mango, X. citri pv. mangiferaeindicae naturally infects another species in the Anacardiaceae family_namely, Brazilian pepper (Schinus terebinthifolius)—although host specialization of the bacterial strains involved occurs (Gagnevin and Pruvost 2001). In the original description of the causal bacterium (Patel et al. 1948), cashew (Anacardium occidentale, Anacardiaceae) was mentioned as a host species after artificial inoculation. However, no outbreaks on cashew have been documented in the scientific literature from India or any other Asian country. Moreover, no X. citri pv. mangiferaeindicae culture from cashew has been deposited in international bacterial culture collections. Therefore, the status of cashew as a host species of $X$. citri pv. mangiferaeindicae is unclear. In Brazil, cashew is affected by another bacterial pathogen, $X$. citri pv. anacardii (syn. X. axonopodis pv. anacardii) and both yellowpigmented and nonpigmented strains of this pathovar have been reported (Ah-You et al. 2007, 2009; Gama et al. 2011). The cashew pathogen in Brazil was previously misclassified as pv. mangiferaeindicae (Robbs et al. 1982). X. citri pv. anacardii is opportunistic on mango and does not induce typical symptoms of MBC (Ah-You et al. 2007). The bacterium induces leaf, fruit, and twig lesions on cashew but no symptoms on pseudofruit have been reported to date (Gama et al. 2011). Nonpigmented strains primarily produce angular leaf spots on cashew leaves while yellow-pigmented strains also induce black symptoms in the leaf veins and surrounding tissues, which may spread to secondary veins and petioles and eventually produce twig necrosis (Gama et al. 2011).

Both members of the $X$. citri genomospecies, pv. mangiferaeindicae and pv. anacardii, belong to genetic clusters 9.5 and 9.6, respectively, as defined by Rademaker et al. (2005). These clusters correspond to subgroups 1 and 2, respectively, in the recently emended description of the $X$. citri species (Constantin et al. in press). Consequently, in addition to pathogenicity tests, both pathovars can be congruently distinguished by several genotyping techniques, including amplified fragment length polymorphism, repetitive polymerase chain reaction (PCR), ligation-mediated PCR targeting the IS1595 insertion sequence, and multilocus sequence analysis (AhYou et al. 2007; Bui Thi Ngoc et al. 2010; Gama et al. 2011; Pruvost et al. 2011c). 
Here, we report a major outbreak caused by X. citri pv. mangiferaeindicae on cashew in Burkina Faso (Comoe and Kenedougou Provinces). We present a comprehensive molecular and pathological characterization of the associated isolates obtained, and discuss the agricultural significance of the disease.

\section{Materials and Methods}

Bacterial isolates and media. In total, 162 isolates of $X$. citri pv. mangiferaeindicae obtained from mango and cashew in 2014 to early 2015 in the provinces of Kenedougou and Comoe in Burkina Faso were a basis for this study (Supplementary Table S1). Isolates were purified from single colonies on kasugamycin-cephalexin (KC) semiselective medium, as reported previously (Pruvost et al. 2005). Cultures were stored at $-80^{\circ} \mathrm{C}$ in Microbank vials (Fisher Scientific, Illkirch, France). Cultures were isolated on yeast-peptone-glucoseagar (YPGA) incubated at $28^{\circ} \mathrm{C}$ for 3 to 4 days, as detailed earlier (Ah-You et al. 2007). The X. citri pv. mangiferaeindicae pathotype strain CFBP 1716 was used as a control in each experiment. After characterization, three strains $X$. citri pv. mangiferaeindicae from cashew were deposited in the Collection Française de Bactéries associées aux Plantes (CFBP), Angers, France (http://www6. inra.fr/cirm/CFBP-Bacteries-associees-aux-Plantes) as CFBP 8395 (LM003-1), 8396 (LM004-1) and 8397 (LM006-1).

Multilocus sequence analysis. Seven $X$. citri pv. mangiferaeindicaelike isolates (LM001-1, LM002-1, LM003-1, LM004-1, LM005-1, LM006-1, and LM007-1) from cashew in Burkina Faso in 2015 were assayed. The produced genomic sequences were compared with those obtained previously for three isolates (LH127-2, LH130-1, and LH131-1) isolated from mango in Burkina Faso in 2010 (Pruvost et al. 2011b) and the pathotype strain of X. citri pv. mangiferaeindicae (CFBP 1716; Bui Thi Ngoc et al. 2010). Four housekeeping gene portions ( $a t p D$, dnaK, efp, and gyrB) were targeted as described previously (Bui Thi Ngoc et al. 2010). Briefly, all PCR amplifications were performed in 50- $\mu$ l reaction mixtures using the BD Advantage 2 polymerase mix kit (Takara Bio Europe/Clontech, Saint-Germainen-Laye, France). PCR was performed as follows: heating to $95^{\circ} \mathrm{C}$ for $3 \mathrm{~min}$; 35 cycles of denaturation for $1 \mathrm{~min}$ at $95^{\circ} \mathrm{C}$, annealing for $1 \mathrm{~min}$ at $66^{\circ} \mathrm{C}$, and extension for $1 \mathrm{~min}$ at $68^{\circ} \mathrm{C}$; followed by a final extension step at $68^{\circ} \mathrm{C}$ for $7 \mathrm{~min}$. The amplicons were sequenced using the Sanger technology (single-pass double-strand analysis) by Beckman Coulter Genomics (Takeley, UK). Sequence alignments were generated using Geneious R8 v8.0.4 with the Geneious alignment option.

Pathogenicity tests on cashew and mango. $X$. citri pv. mangiferaeindicae isolates LM003-1, LM004-1, and LM006-1 (obtained from cashew in Burkina Faso) and LH127-2 and LH131-1 (previously obtained from mango in Burkina Faso) (Pruvost et al. 2011b) were used for inoculations. Mango ('Maison Rouge') and cashew ('Jaune' local accession) seedlings were used for inoculations, as reported previously (Ah-You et al. 2007). Experiments were replicated once. Briefly, bacterial suspensions in Tris buffer containing approximately $1 \times 10^{5} \mathrm{CFU} \mathrm{ml}{ }^{-1}$ were infiltrated $\left(0.3\right.$ to $\left.0.4 \mathrm{~cm}^{2}\right)$ into the mesophyll of mature leaves from the youngest vegetative flush. Sterile Tris buffer and strain $X$. citri pv. mangiferaeindicae CFBP 1716 were used as negative and positive controls, respectively. For each isolate and controls, 10 inoculations were performed on each of three leaves on different plants. Each experiment was replicated once. Plants were placed in growth chambers at $30 \pm 1{ }^{\circ} \mathrm{C}$ (day) and $26 \pm 1{ }^{\circ} \mathrm{C}$ (night) and $80 \pm$ $10 \%$ relative humidity for 35 days with a photoperiod of $12 \mathrm{~h}$. All inoculated leaves were examined daily for lesion development (i.e., the number of visible lesions per leaf). X. citri pv. mangiferaeindicae population sizes in lesions from the two plant species assayed were estimated 35 days after inoculation (dai). For each isolate-host or strain-host combination, 12 leaf fragments showing symptoms (approximately $1 \mathrm{~cm}^{2}$ ) collected from inoculation sites were sampled and individually homogenized in Tris buffer. Aliquots of the homogenized suspensions and of 10-fold serial dilutions obtained from the suspensions were plated on $\mathrm{KC}$ semiselective medium using a Spiral System plater device (Interscience, Saint Nom la Bretèche, France) (Pruvost et al. 2005). Bacterial population sizes were based on enumeration of $X$. citri pv. mangiferaeindicae-like CFUs. Doubtful colonies were checked for starch hydrolysis (Pruvost et al. 1998). For verifying Koch's postulates of the cashew isolates, one bacterial colony from each assayed isolate reisolated from cashew and mango 35 dai was subjected to $a t p D$ gene sequencing, as described above. The area under disease progress curve (AUDPC) was calculated with the R package 'agricolae' for each inoculated leaf (Campbell and Madden 1990).

Strain and host effect on bacterial population sizes were examined with analysis of variance (ANOVA; Fisher's least significant difference). Data were transformed using the boxcox function (MASS package). Tuckey's all-pair comparison tests (multcomp package) were used if the ANOVA test was significant. All tests were conducted at the significance level of 0.05 .

Multilocus variable number of tandem repeat analysis. A multilocus variable number of tandem repeat analysis targeting 12 loci (MLVA-12) is useful for investigations of phytobacterial disease outbreaks at small evolutionary scales (Pruvost et al. 2011c). MLVA-12 genotyping was applied to the whole isolate collection, as described earlier (Pruvost et al. 2011c), except that the Terra PCR direct polymerase mix (Clontech) was used instead of the Qiagen multiplex PCR kit and the primer concentration was increased to $0.6 \mu \mathrm{M}$ for the XL8 and XL13 loci and to $0.3 \mu \mathrm{M}$ for all other markers. Strain CFBP 1716 was used as a control in each MLVA microplate. Briefly, the 12 tandem repeat (TR) loci were amplified in a multiplex PCR format. For each locus, one of each primer was $5^{\prime}$-labeled with 6-FAM, NED, PET, or VIC (Applied Biosystems, Courtaboeuf, France). PCR reactions containing $1 \mu \mathrm{l}$ of bacterial cell suspension of a pure culture grown overnight on YPGA as the template in $15-\mu$ l volumes were performed as follows: $2 \mathrm{~min}$ at $98^{\circ} \mathrm{C}$ for hot-start activation; 25 cycles of denaturation at $98^{\circ} \mathrm{C}$ for $10 \mathrm{~s}$, annealing at temperatures ranging from $64^{\circ} \mathrm{C}$ (pools 3 and 4 ) to $68^{\circ} \mathrm{C}$ (pools 1 and 2) for $15 \mathrm{~s}$, and extension at $68^{\circ} \mathrm{C}$ for $1 \mathrm{~min}$; and a final extension step at $68^{\circ} \mathrm{C}$ for $30 \mathrm{~min}$. Capillary electrophoresis was performed in an ABI PRISM-3130XL genetic analyzer (Applied Biosystems). MLVA data scoring and exploration were conducted as follows. Densitograms were analyzed using GeneMapper 4.0 (Applied Biosystems) and transformed as TR integers to be used as input data. All strains were genotyped at all loci. Categorical minimum-spanning trees were built using the algorithm recommended for MLVA data combining global optimal eBURST (goeBURST) and Euclidean distances in PHYLOViZ v1.0 (Francisco et al. 2012). Similarly, the delineation of clonal complexes (CC) (i.e., haplotypes differing at a single TR locus, also referred to as single-locus variants) was achieved using the same algorithm in PHYLOViZ v1.0. Nei's unbiased estimates of genetic diversity $\left(\mathrm{H}_{\mathrm{E}}\right)$ were calculated with ARLEQUIN version 3.5 (Excoffier et al. 2005). Allelic richness $(A)$ and private allelic richness $\left(A_{P}\right)$ were calculated using the rarefaction procedure for unequal sample sizes with HP-RARE, version 1.0 (Kalinowski 2005). Pairwise $R_{\text {ST }}$ values were computed for estimating genetic differentiation at the local population level (i.e., between groves) as well as between provinces and host species. Significance was tested with 1,000 permutations using ARLEQUIN 3.5.

\section{Results}

Symptomatology on cashew in Burkina Faso. Leaf and fruit symptoms were commonly observed on cashew trees. Typical leaf lesions started as small, angular, water-soaked spots, which eventually coalesced. Lesions turned into flat, dark-brown to black necrotic angular spots often surrounded by a yellowish halo (Fig. 1A). Lesions were observed along the primary and secondary leaf veins (Fig. 1B). The necrotic spots are flat or slightly raised under natural conditions (Figs. 1A and B) but also after infiltration leaf inoculations (Fig. 1C). Over time, the necrotic spots turned ash gray in color. Severe leaf infections resulted in partial tree defoliation. On cashew fruit, symptoms started as water-soaked spots, which often produced gummy exudate droplets with a "tear stain" pattern that turn black in a later stage (Fig. 1D). Severe fruit infections reduced fruit quality and caused premature fruit drop. In apparent contrast to the situation in Brazil (Gama et al. 2011), symptoms in Burkina Faso were also observed on the pseudofruit (Fig. 1E) and on green shoots (Fig. 1F). Nonpigmented Xanthomonas-like colonies were readily isolated from the lesions on each organ using $\mathrm{KC}$ semiselective medium. Pure 
cultures from colonies recovered from at least three independent leaf, fruit, and shoot samples were shown to be pathogenic when inoculated to mango. Nonpigmented Xanthomonas-like pure cultures from the produced lesions were obtained on $\mathrm{KC}$ semiselective plates and further identified as $X$. citri pv. mangiferaeindicae based on atpD sequencing, thus fulfilling Koch's postulates.

Multilocus sequence analysis. All assayed isolates from cashew and mango in Burkina Faso yielded sequences that were indistinguishable from the pathotype strain of $X$. citri pv. mangiferaeindicae, regardless of the gene assayed (GenBank accessions EU015189, EU015281, EU015373, and FJ376236). However, they differed from any other assayed $X$. citri pathovar, including $X$. citri $\mathrm{pv}$. anacardii pathogenic to cashew in Brazil (for details about phylogenetic relatedness of $X$. citri pv. mangiferaeindicae to other $X$. citri pathovars, see Ah-You et al. [2009] and Bui Thi Ngoc et al. [2010]).

Pathogenicity tests on cashew and mango. All tested $X$. citri pv. mangiferaeindicae isolates or strains induced black lesions on mango and cashew leaves at all inoculation sites 11 dai. The lesions

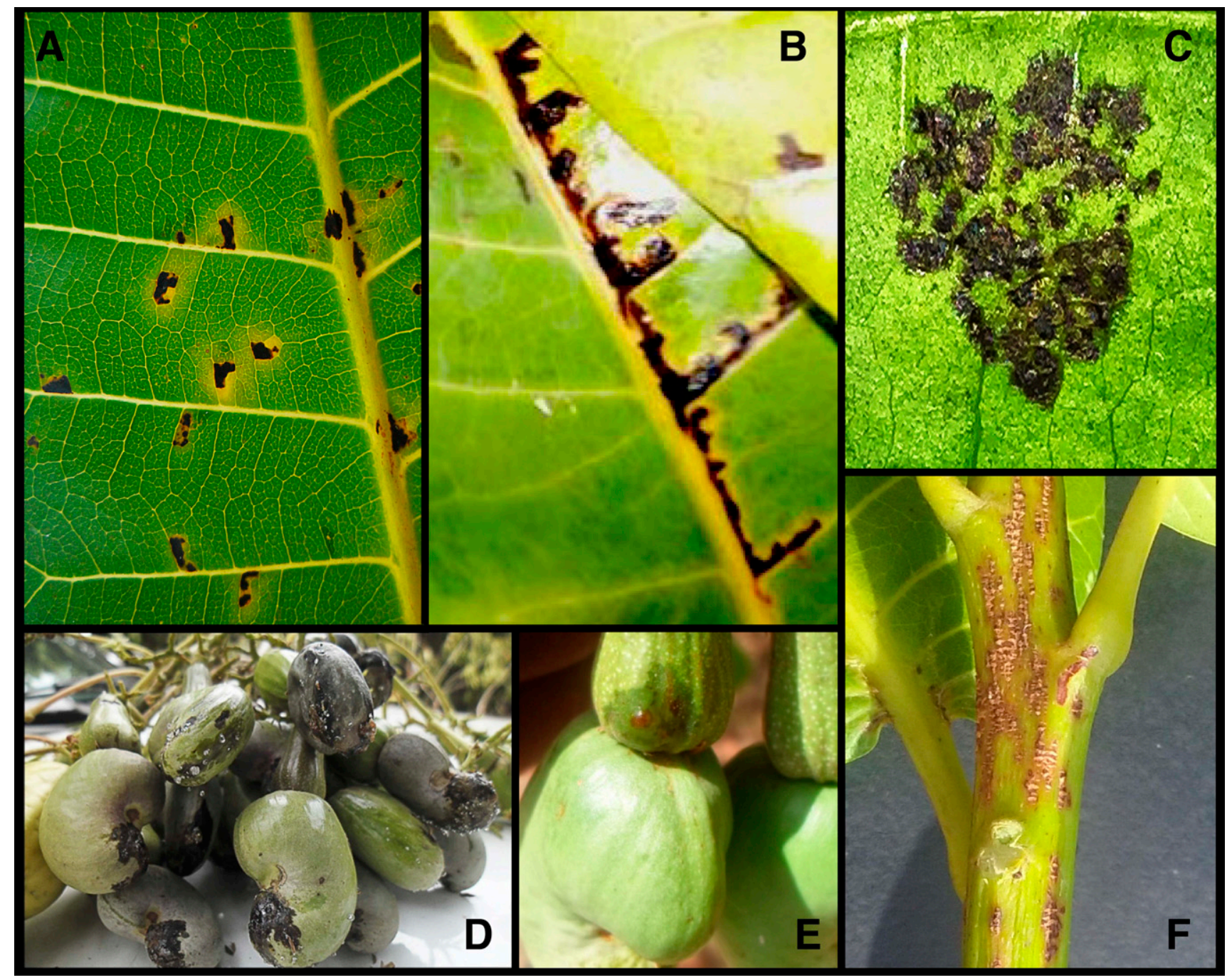

Fig. 1. Typical symptoms observed on cashew infected with Xanthomonas citri pv. mangiferaeindicae. A, Typical angular leaf symptoms (approximately 1 month old). B, Leaf lesions along the primary and secondary leaf veins. C, Lesions on inoculated leaves (11 days old from infiltration of a bacterial suspension containing approximately $1 \times 10^{5} \mathrm{CFU} \mathrm{ml}^{-1}$ ). D, Typical fruit symptoms (note the presence of gummy exudate). E, Water-soaked lesion from a pseudofruit. F, Brownish lesion on herbaceous shoot.

Table 1. Lesion development based on area under disease progress curves (AUDPC) after inoculation of cashew and mango leaves with Xanthomonas citri pv. mangiferaeindicae strains isolated from these two host species in Burkina Faso

\begin{tabular}{|c|c|c|c|c|c|}
\hline \multirow[b]{2}{*}{ Strain } & \multirow[b]{2}{*}{ Host of origin } & \multirow[b]{2}{*}{ Country of origin } & \multirow[b]{2}{*}{ Pathovar } & \multicolumn{2}{|c|}{ AUDPC } \\
\hline & & & & Cashew & Mango \\
\hline CFBP $1716^{z}$ & Mango & India & mangiferaeindicae & $41.3(1.25)$ & $24.6(1.17)$ \\
\hline LM003-1 & Cashew & Burkina Faso & mangiferaeindicae & $42.8(1.11)$ & $20.0(2.24)$ \\
\hline LM004-1 & Cashew & Burkina Faso & mangiferaeindicae & $43.8(0.79)$ & $22.0(1.69)$ \\
\hline LM006-1 & Cashew & Burkina Faso & mangiferaeindicae & $42.8(1.25)$ & $23.3(1.67)$ \\
\hline LH 127-2 & Mango & Burkina Faso & mangiferaeindicae & $41.3(1.76)$ & $20.5(2.06)$ \\
\hline LH 131-1 & Mango & Burkina Faso & mangiferaeindicae & $44.0(0.45)$ & $20.0(2.24)$ \\
\hline
\end{tabular}

y AUDPC values were based on lesion development on 10 inoculation sites per leaf. In total, six AUDPC values per strain-host combination were used to calculate mean and standard errors (in parentheses). A significant host effect on AUDPC values was observed. No significant differences among strains were identified whatever the host species assayed.

z Pathotype strain used as positive control. 
appeared to be slightly more raised on mango than on cashew, a feature that was not strain dependent. No lesions developed from the negative control consisting of sterile buffer. Based on ANOVA $\left(P<2 \times 10^{-16}\right)$, AUDPC was found to be larger on cashew (41.3 to 44.0 ) than on mango (20.0 to 24.6$)$ (Table 1$)$. This primarily indicates that visible lesions develop earlier on cashew. Within each plant species, no statistically significant difference for AUDPC was observed between the isolates.

Mean X. citri pv. mangiferaeindicae population sizes estimated for each isolate-host or strain-host combination 35 dai always exceeded $1 \times 10^{7} \mathrm{CFU}$ lesion $^{-1}$ (Table 2). On cashew, population sizes ranged from $1.6 \times 10^{7}$ to $3.2 \times 10^{7} \mathrm{CFU}$ lesion $^{-1}$ for all isolates, regardless of their host of origin. The same isolates inoculated on mango produced slightly larger population sizes (from $5.5 \times 10^{7}$ to $1.4 \times 10^{8} \mathrm{CFU}$ lesion $\left.^{-1}\right)$. The analysis of variance indicated a significant host species $\left(P<2 \times 10^{-16}\right)$ and strain $(P<0.0001)$ effect on bacterial population size. On cashew, population sizes did not differ significantly between isolates. Although some significant differences in bacterial population sizes were found between isolates when inoculated on mango (Table 2), there was no clear relationship between host of origin and population size. Colonies recovered from lesions were reidentified as the target (100\% nucleotide identity) by atpD sequencing, thus fulfilling Koch's postulates on cashew.

MLVA-12. This technique made it possible to conduct genotyping at all targeted TR loci for all isolates from cashew and mango in Comoe and Kenedougou Provinces. This confirmed their classification as X. citri pv. mangiferaeindicae and not X. citri pv. anacardii, because the latter bacterium yielded amplicons at only four TR loci (Pruvost et al. 2011c). Three loci (XL6, XL9, and XL10) were monomorphic (Supplementary Table S2). XL6 and XL10 were identified previously as a polymorphic locus displaying the lowest diversity and a monomorphic locus, respectively. In a previous study analyzing a worldwide strain collection, the allelic range of XL9 was 4 to 26 TR (Pruvost et al. 2011c). All strains from Burkina Faso assayed here had four TR at XL9. Arrays with low TR numbers typically display low polymorphism (Pourcel and Vergnaud 2011; Van Belkum et al. 1998). Overall, the genetic diversity was moderate and similar for the strains originating from the two host species $\left(\mathrm{H}_{\mathrm{E}}=0.342\right.$ and 0.297 for cashew and mango, respectively; and $\mathrm{A}=3.17$ [ $n=78]$ for both species). Low A values $(2.33 \leq \mathrm{A} \leq 2.75)$ were obtained when considering each host speciesprovince combination and, therefore, consistent with the pathogen's relatively recent establishment in Burkina Faso (Pruvost et al. 2011b). $\mathrm{A}_{\mathrm{P}}$ was also very low $\left(0.09 \leq \mathrm{A}_{\mathrm{P}} \leq 0.40\right)$, slightly higher in Kenedougou Province $\left(0.24 \leq A_{P} \leq 0.40\right)$ than in Comoe Province $\left(0.09 \leq \mathrm{A}_{\mathrm{P}} \leq 0.11\right)$.

In all, 42 haplotypes were distinguished among the 162 strains studied. Eleven of the haplotypes were detected in strains originating from mango and cashew. The minimum spanning tree (Fig. 2) suggested a lack of host-dependent genetic structuration. The population in Burkina Faso was structured as seven CC and six singletons (i.e., strains not sharing single-locus variations with any other strain sampled). The predicted founders (i.e., the haplotype that shared the highest number of single-locus variants in the $\mathrm{CC}$ ) of the three major $\mathrm{CC}$ (which, when combined, represent $80 \%$ of the strains) were haplotypes 1 (number of strains in the CC: $n=56$; number of strains assigned to the founder: $n=19), 14(n=25 ; n=10)$, and $7(n=$ $48 ; n=17$ ), respectively (Fig. 2).

Globally, no genetic differentiation $\left(\mathrm{R}_{\mathrm{ST}}=0.016, P=0.099\right)$ was revealed between strains isolated from cashew and mango. Additionally, at the orchard scale, some populations originating from different hosts were not significantly genetically differentiated or weakly differentiated (Table 3).

\section{Discussion}

Since MBC caused by $X$. citri pv. mangiferaeindicae was first reported in 2010 in Ghana, it has been found to have a high prevalence and a wide geographical distribution in Western Africa (Pruvost et al. 2011a,b, 2012, 2014; Zombre et al. 2015). Here, we present the first report of a bacterial canker and leaf spot on cashew caused by $X$. citri

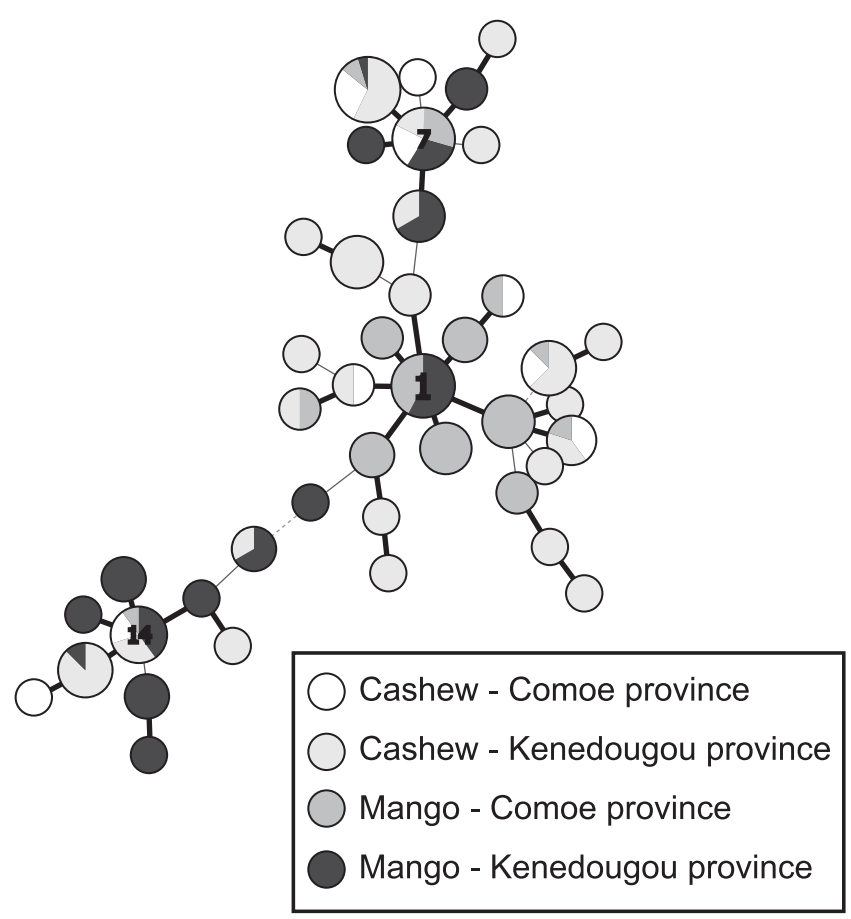

Fig. 2. Categorical minimum spanning tree of Xanthomonas citri pv. mangiferaeindicae strains sampled in Burkina Faso from cashew and mango (162 isolates, 42 haplotypes) based on microsatellite data (multilocus variable number of tandem repeat analysis targeting 12 loci). Dot diameter is representative of the number of strains per haplotype. Single and multiple locus variations (i.e., double and triple locus variations were observed in the dataset) are represented as thick solid, thin solid, and thin dotted lines joining haplotypes, respectively. Numbers inside dots correspond to haplotype (WA) numbers of the founders of the three major clonal complexes.

Table 2. Bacterial population sizes recorded from leaf lesions 35 days after inoculation of cashew and mango leaves with Xanthomonas citri pv. mangiferaeindicae strains isolated from these two host species in Burkina Faso

\begin{tabular}{lccccc}
\hline & & & & \multicolumn{2}{c}{ Log-transformed CFU lesion $^{-1 \mathbf{y}}$} \\
\cline { 3 - 6 } Strain & Host of origin & Country of origin & Pathovar & Cashew & Mango \\
\hline CFBP 1716 & Mango & India & mangiferaeindicae & $7.45(0.080)$ & $7.88(0.083)$ abc \\
LM003-1 & Cashew & Burkina Faso & mangiferaeindicae & $7.35(0.093)$ & $7.74(0.043) \mathrm{c}$ \\
LM004-1 & Cashew & Burkina Faso & mangiferaeindicae & $7.22(0.089)$ & $7.81(0.054) \mathrm{bc}$ \\
LM006-1 & Cashew & Burkina Faso & mangiferaeindicae & $7.51(0.066)$ & $8.06(0.060) \mathrm{a}$ \\
LH127-2 & Mango & Burkina Faso & mangiferaeindicae & $7.49(0.056)$ & $7.99(0.053) \mathrm{ab}$ \\
LH131-1 & Mango & Burkina Faso & mangiferaeindicae & $7.31(0.083)$ & $7.82(0.043) \mathrm{bc}$ \\
\hline
\end{tabular}

y Population sizes were determined on KC semiselective medium. Twelve lesions per strain-host combination were used to assess population size. Standard errors are provided in parentheses. Strain comparisons based on Tukey's all-pair comparison tests were conducted for the mango dataset. Population size values with the same letters did not differ significantly $(P=0.05)$. No significant difference among population sizes was found on cashew based on analysis of variance.

z Pathotype strain. 
pv. mangiferaeindicae in Burkina Faso. Although more data are required for an accurate assessment of losses, the damage observed in the diseased orchards suggests a putative loss of vigor of diseased trees and a major depreciation in the quality and commercial value of cashew nuts. The spread of this cashew disease could become crucial for Burkina Faso's neighbor, Ivory Coast, which is recognized as the world's second-largest cashew producer (an estimated 18\% of total world production, equivalent to approximately 2.6 millions tons in 2013; www.cashewinfo.com/cashewhandbook2014.pdf). It is also of importance for several other West African countries, including Burkina Faso, because, over the last decade, they have collectively become the world's primary cashew-producing region. In Burkina Faso, the cashew industry is increasingly important. Cashew is presently grown on approximately 80,000 ha, producing an estimated yield of 30,000 metric tons (Audouin and Gonin 2014). Most of the cashew industry is located in the provinces of Comoe, Poni, Kenedougou, and Houet.

In this article, the symptomatology described on cashew in Burkina Faso is mostly similar to that reported for cashew bacterial spot caused by X. citri pv. anacardii in Brazil (Ah-You et al. 2007; Gama et al. 2011). The main noticeable difference was the observation of typical lesions on pseudofruit in Burkina Faso that has not as yet been observed in Brazil (Gama et al. 2011). Given that the symptoms induced on cashew by $X$. citri pv. mangiferaeindicae and X. citri pv. anacardii are quite similar despite genetically distinct causal agents, we conclude that xanthomonads pathogenic on cashew may represent another case of pathological convergence in this bacterial genus. Pathological convergence has previously been demonstrated for xanthomonads causing (i) bacterial spot of tomato or pepper, (ii) bacterial blight of bean, and (iii) citrus canker (Jones et al. 1998; Mhedbi-Hajri et al. 2013; Pruvost et al. 2015).

Our study clarifies the status of cashew as a natural host species of $X$. citri pv. mangiferaeindicae, which has been unclear since the original description of the bacterium in the 1940s (Patel et al. 1948). From pathogenicity assays, we found that lesions developed earlier on cashew, although bacterial population sizes in lesions were significantly lower (i.e., less than one log unit) than on Maison Rouge mango. When compared with previous results by our group (Ah-You et al. 2007), present results suggest that the bacterial population sizes in cashew lesions may be cashew accession dependent, a situation well known on mango (Gagnevin and Pruvost 2001). Nevertheless, in both studies, population sizes exceeding $1 \times 10^{7} \mathrm{CFU}$ lesion $^{-1}$ were observed on both plant species, typical of a compatible interaction (Ah-You et al. 2007; Bayles and Johnson 1985; Robinson and Callow 1986). Similar population sizes were previously recorded from cashew leaf inoculations with $X$. citri pv. anacardii following the same experimental procedure (Ah-You et al. 2007). The apparent lack of host specialization recorded here and previously between mango and cashew strains of $X$. citri $\mathrm{pv}$. mangiferaeindicae is markedly different from that encountered for Brazilian pepper. The latter is another species in the Anacardiaceae family, which has also been reported as a natural host of this pathovar where there is evidence of host specialization (Gagnevin and Pruvost 2001). Brazilian pepper strains multiply to a lesser extent (by one to four log units) on mango than on the host species from which they originated. Similarly, mango strains reach lower population sizes on Brazilian pepper (Ah-You et al. 2007). Here, the moderate differences in population sizes that were highlighted were not specific to a heterologous interaction (i.e., a strain that was inoculated in a plant species different from that from which it originated). Lesions produced on the mango cultivar assayed yielded slightly larger population sizes than those on cashew, regardless of the strain's original host (Table 2). It is not yet clear whether all $X$. citri pv. mangiferaeindicae mango strains, which are structured into several genetic lineages (Ah-You et al. 2007; Gagnevin et al. 1997), are capable of infecting cashew naturally. However, although genetically distant, the pathotype strain of $X$. citri pv. mangiferaeindicae isolated in India demonstrated the same pathogenicity patterns as strains from Burkina Faso. Further clarifying this point will require additional pathogenicity data and a comparative genomic analysis of $X$. citri pv. mangiferaeindicae strains from different host species and genetic lineages.

The apparent lack of host specialization is consistent with the absence of a genetic distinction in the isolates originating from outbreaks of bacterial canker in mango and cashew in Burkina Faso: (i) strains from both hosts shared identical MLVA haplotypes, (ii) no overall genetic differentiation was observed between strains isolated from cashew and mango, and (iii) an absence of or only weak differentiation was observed between populations from cashew and mango originating from different locations. Consistently, the minimum spanning tree built from microsatellite data also suggested a lack of host-dependent structure. In addition, identical haplotypes or populations that are not genetically differentiated were found in different provinces, suggesting longdistance migration events. Producers in Burkina Faso (and other West African countries) have mixed orchards (e.g., $>50 \%$ of farms in the provinces of Comoe, Houet, Noumbiel, Poni, and Sissili), where both mango and cashew are sometimes close together. Consequently, wind-driven or human-assisted dispersal (e.g., through grove maintenance operations) of the bacterium from one plant species to another is likely. Most cashew groves in Burkina Faso are primarily established from seedlings produced on site. In contrast, mango nurseries are widespread, which facilitates the long-distance spread of pathogens. In the case of bacterial diseases of perennial crop species, propagative plant material typically constitutes a major pathway for disease spread (Gagnevin and Pruvost 2001; Gottwald et al. 2002; Leduc et al. 2015; Vernière et al. 2014).

We conclude that cashew and mango are two host species affected by a single disease outbreak caused by $X$. citri $\mathrm{pv}$. mangiferaeindicae in Burkina Faso. Both hosts can play the role of reservoir or alternative host, thus contributing to the spread of the pathogen. In order to improve control in West Africa, disease management will have to consider both hosts simultaneously.

Table 3. Genetic differentiation estimated by pairwise $\mathrm{R}_{\mathrm{ST}}$ comparisons among different populations of Xanthomonas citri pv. mangiferaeindicae isolated from cashew and mango in the Comoe and Kenedougou Provinces of Burkina Faso ${ }^{y}$

\begin{tabular}{|c|c|c|c|c|c|c|c|}
\hline \multirow[b]{3}{*}{ Locality ${ }^{z}$} & \multicolumn{3}{|c|}{ Cashew } & \multicolumn{4}{|c|}{ Mango } \\
\hline & \multirow{2}{*}{$\frac{\text { Comoe }}{\text { Berega1 }}$} & \multicolumn{2}{|c|}{ Kenedougou } & \multicolumn{2}{|c|}{ Comoe } & \multicolumn{2}{|c|}{ Kenedougou } \\
\hline & & Koloko1 & Koloko2 & Berega2 & Banfora & Koloko3 & Koloko4 \\
\hline Koloko1 & $0.038 \mathrm{NS}$ & $\ldots$ & $\ldots$ & $\ldots$ & $\ldots$ & $\ldots$ & $\ldots$ \\
\hline Koloko2 & $0.374 * * *$ & $0.536 * * *$ & $\ldots$ & $\ldots$ & $\ldots$ & $\ldots$ & $\ldots$ \\
\hline Berega2 & $0.274 * * *$ & $0.315 * * *$ & $0.585^{* * * *}$ & $\ldots$ & $\ldots$ & $\ldots$ & $\ldots$ \\
\hline Banfora & $0.088 \mathrm{NS}$ & $0.119^{*}$ & $0.508 * * *$ & $0.118^{*}$ & $\ldots$ & $\ldots$ & $\ldots$ \\
\hline Koloko3 & $0.115 \mathrm{NS}$ & $0.296 * * *$ & $0.168^{*}$ & $0.437 * * *$ & $0.281 * * *$ & $\ldots$ & $\ldots$ \\
\hline Koloko4 & $0.084 \mathrm{NS}$ & $0.226 * * *$ & $0.135^{*}$ & $0.299 * * *$ & $0.178 * *$ & $0.024 \mathrm{NS}$ & $\ldots$ \\
\hline
\end{tabular}

y Asterisks ***, **, and $*$ indicate $P$ values $<0.001,0.01$, and 0.05 , respectively; NS $\geq 0.05$.

${ }^{\mathrm{z}}$ Different sites from Beregadougou (Berega), Koloko, and Banfora. 


\section{Acknowledgments}

We thank A. W. Grondin and V. Ledoux for their technical assistance. The European Union (ERDF), Conseil Régional de La Réunion, and CIRAD provided financial support. C. Zombre acknowledges support from the West African Productivity Program (WAAPP) for funding field surveys in Burkina Faso, as well as travel and research expenses during his stay in Réunion Island.

\section{Literature Cited}

Ah-You, N., Gagnevin, L., Chiroleu, F., Jouen, E., Neto, J. R., and Pruvost, O. 2007. Pathological variations within Xanthomonas campestris pv. mangiferaeindicae support its separation into three distinct pathovars that can be distinguished by amplified fragment length polymorphism. Phytopathology 97:1568-1577.

Ah-You, N., Gagnevin, L., Grimont, P. A. D., Brisse, S., Nesme, X., Chiroleu, F., Bui Thi Ngoc, L., Jouen, E., Lefeuvre, P., Vernière, C., and Pruvost, O. 2009. Polyphasic characterization of xanthomonads pathogenic to Anacardiaceae and their relatedness to different Xanthomonas species. Int. J. Syst. Evol. Microbiol. 59:306-318.

Audouin, S., and Gonin, A. 2014. L'anacarde: produit de la globalisation, moteur de la territorialisation, l'exemple du Sud du Burkina Faso. Online publication. EchoGéo 29.

Bayles, M. B., and Johnson, W. M. 1985. Growth of homologous and heterologous phytopathogenic bacteria in cotton lines susceptible, resistant, or immune to blight. Phytopathology 75:515-519.

Bui Thi Ngoc, L., Vernière, C., Jouen, E., Ah-You, N., Lefeuvre, P., Chiroleu, F., Gagnevin, L., and Pruvost, O. 2010. Amplified fragment length polymorphism and multilocus sequence analysis-based genotypic relatedness among pathogenic variants of Xanthomonas citri pv. citri and Xanthomonas campestris pv. bilvae. Int. J. Syst. Evol. Microbiol. 60:515-525.

Campbell, C. L., and Madden, L. V. 1990. Introduction to Plant Disease Epidemiology. John Wiley \& Sons, New York.

Constantin, E. C., Cleenwerck, I., Maes, M., Baeyen, S., Van Malderghem, C., De Vos, P., and Cottyn, B. Genetic characterisation of strains named as Xanthomonas axonopodis pv. dieffenbachiae leads to a taxonomic revision of the $X$. axonopodis species complex. Plant Pathol. In press. doi: 10.1111/ppa.12461

Dye, D. W., Bradbury, J. F., Goto, M., Hayward, A. C., Lelliott, R. A., and Schroth, M. N. 1980. International standards for naming pathovars of phytopathogenic bacteria and a list of pathovar names and pathotype strains. Rev. Plant Pathol. 59:153-168.

Excoffier, L., Laval, G., and Schneider, S. 2005. Arlequin (version 3.0): An integrated software package for population genetics data analysis. Evol. Bioinf. 1:47-50.

Francisco, A. P., Vaz, C., Monteiro, P. T., Melo-Cristino, J., Ramirez, M., and Carriço, J. A. 2012. PHYLOViZ: Phylogenetic inference and data visualization for sequence based typing methods. BMC Bioinf. 13:87.

Gagnevin, L., Leach, J. E., and Pruvost, O. 1997. Genomic variability of the Xanthomonas pathovar mangiferaeindicae, agent of mango bacterial black spot. Appl. Environ. Microbiol. 63:246-253.

Gagnevin, L., and Pruvost, O. 2001. Epidemiology and control of mango bacterial black spot. Plant Dis. 85:928-935.

Gama, M. A. S., Mariano, R. L. R., Viana, F. M. P., Ferreira, M. A. S. V., and Souza, E. B. 2011. Polyphasic characterization of pigmented strains of Xanthomonas pathogenic to cashew trees. Plant Dis. 95:793-802.

Gottwald, T. R., Graham, J. H., and Schubert, T. S. 2002. Citrus canker: The pathogen and its impact. Online publication. Plant Health Prog. doi: 10.1094/PHP-2002-0812-01-RV

Jones, J. B., Stall, R. E., and Bouzar, H. 1998. Diversity among xanthomonads pathogenic on pepper and tomato. Annu. Rev. Phytopathol. 36:41-58.

Kalinowski, S. T. 2005. HP-RARE 1.0: A computer program for performing rarefaction on measures of allelic richness. Mol. Ecol. Notes 5:187-189.

Kishun, R. 1982. Loss in mango fruit due to bacterial canker Xanthomonas mangiferaeindicae. Pages 181-184 in: Plant Pathogenic Bacteria. J. C. Lozano, ed. CIAT, Cali, Columbia.

Leduc, A., Traoré, Y. N., Boyer, K., Magne, M., Grygiel, P., Juhasz, C., Boyer, C., Guérin, F., Wonni, I., Ouedraogo, L., Vernière, C., Ravigné, V., and Pruvost, O. 2015. Bridgehead invasion of a monomorphic plant pathogenic bacterium: Xanthomonas citri pv. citri, an emerging citrus pathogen in Mali and Burkina Faso. Environ. Microbiol. 17:4429-4442.
Manicom, B. Q., and Wallis, F. M. 1984. Further characterization of Xanthomonas campestris pv. mangiferaeindicae. Int. J. Syst. Bacteriol. 34:77-79.

Mhedbi-Hajri, N., Hajri, A., Boureau, T., Darrasse, A., Durand, K., Brin, C., Fischer-Le Saux, M., Manceau, C., Poussier, S., Pruvost, O., Lemaire, C., and Jacques, M. A. 2013. Evolutionary history of the plant pathogenic bacterium Xanthomonas axonopodis. PLoS One 8:e58474.

Midha, S., and Patil, P. B. 2014. Genomic insights into the evolutionary origin of Xanthomonas axonopodis pv. citri and its ecological relatives. Appl. Environ. Microbiol. 80:6266-6279.

Mukherjee, S. K. 1997. Introduction: Botany and importance. Pages 1-21 in: The Mango: Botany, Production and Uses. R. E Litz, ed. CAB International, New York and Oxon, UK.

Patel, M. K., Kulkarni, Y. S., and Moniz, L. 1948. Pseudomonas mangiferaeindicae, pathogenic on mango. Indian Phytopathol. 1:147-152.

Pourcel, C., and Vergnaud, G. 2011. Strain typing using multiple "variable number of tandem repeat" analysis and genetic element CRISPR. Pages 179-197 in: Molecular Microbiology: Diagnostic Principles and Practice. D. H. Persing, F. C. Tenover, Y. W. Tang, F. S. Nolte, R. T. Hayden, and A. Van Belkum, eds. ASM Press, Washington, DC.

Pruvost, O., Boyer, C., Grygiel, P., Boyer, K., Verniere, C., Gagnevin, L., Soro, S., N'Guessan, C., and Kone, D. 2014. First report of Xanthomonas citri pv. mangiferaeindicae causing mango bacterial canker on Mangifera indica L. in Ivory Coast. Plant Dis. 98:1740.

Pruvost, O., Boyer, C., Vital, K., Vernière, C., Gagnevin, L., De Bruno Austin, L., and Rey, J. Y. 2011a. First report in Ghana of Xanthomonas citri pv. mangiferaeindicae causing mango bacterial canker on Mangifera indica. Plant Dis. 95:774.

Pruvost, O., Boyer, C., Vital, K., Vernière, C., Gagnevin, L., and Somda, I. 2011b. First report in Burkina Faso of Xanthomonas citri pv. mangiferaeindicae causing mango bacterial canker on Mangifera indica. Plant Dis. 95:1312.

Pruvost, O., Boyer, C., Vital, K., Vernière, C., Gagnevin, L., and Traoré, Y. N. 2012. First report in Mali of Xanthomonas citri pv. mangiferaeindicae causing mango bacterial canker on Mangifera indica. Plant Dis. 96:581.

Pruvost, O., Couteau, A., Perrier, X., and Luisetti, J. 1998. Phenotypic diversity of Xanthomonas sp. mangiferaeindicae. J. Appl. Microbiol. 84:115-124.

Pruvost, O., Roumagnac, P., Gaube, C., Chiroleu, F., and Gagnevin, L. 2005. New media for the semi-selective isolation and enumeration of Xanthomonas campestris pv. mangiferaeindicae, the causal agent of mango bacterial black spot. J. Appl. Microbiol. 99:803-815.

Pruvost, O., Vernière, C., Vital, K., Guérin, F., Jouen, E., Chiroleu, F., Ah-You, N., and Gagnevin, L. 2011c. Insertion sequence- and tandem repeat-based genotyping techniques for Xanthomonas citri pv. mangiferaeindicae. Phytopathology 101:887-893.

Pruvost, O., Wang, N., Robène, I., Escalon, A., Leduc, A., Gagnevin, L., Vernière, C., Schwartz, H. F., Gent, D. H., Rott, P., Royer, M., Alvarez, A. M., Vowell, T. S., Toves, P. M., Potnis, N., White, F. F., and Jones, J. B. 2015. The dynamic world of Xanthomonas. Pages 381-418 in: Virulence Mechanisms of Plant Pathogenic Bacteria. N. Wang, J. B. Jones, G. W. Sundin, F. F. White, S. Hogenhout, C. Roper, L. De La Fuente, and J. H. Ham, eds. American Phytopathological Society, St. Paul, MN.

Rademaker, J. L. W., Louws, F. J., Schultz, M. H., Rossbach, U., Vauterin, L., Swings, J., and De Bruijn, F. J. 2005. A comprehensive species to strain taxonomic framework for Xanthomonas. Phytopathology 95:1098-1111.

Robbs, C. F., Neto, J. R., Ribeiro, R. L. D., and Kimura, O. 1982. Annotated list of bacterial plant pathogens in Brazil. Pages 601-612 in: 5th Int. Conf. Plant Pathol. Bacteriol. J. C. Lozano, ed. CIAT, Cali, Colombia.

Robinson, J. N., and Callow, J. A. 1986. Multiplication and spread of pathovars of Xanthomonas campestris in host and non-host plants. Plant Pathol. 35:169-177.

Van Belkum, A., Scherer, S., Van Alphen, L., and Verbrugh, H. 1998. Shortsequence DNA repeats in prokaryotic genomes. Microbiol. Mol. Biol. Rev. 62:275-293.

Vernière, C., Bui Thi Ngoc, L., Jarne, P., Ravigné, V., Guérin, F., Gagnevin, L., Le Mai, N., Chau, N. M., and Pruvost, O. 2014. Highly polymorphic markers reveal the establishment of an invasive lineage of the citrus bacterial pathogen Xanthomonas citri pv. citri in its area of origin. Environ. Microbiol. $16: 2226-2237$

Zombre, C., Sankara, P., Ouedraogo, L., Wonni, I., Pruvost, O., Boyer, C., Vernière, C., Vayssières, J. F., and Ahohuendo, B. C. 2015. First report of Xanthomonas citri pv. mangiferaeindicae causing mango bacterial canker on Mangifera indica L. in Benin. Plant Dis. 99:1854. 